\title{
Constructing Field Expedient Solar Water Pasteurizers from Junk
}

\author{
Marie C. Johnson* and Andrew R. Pfluger \\ Department of Geography and Environmental Engineering, United States Military Academy, West Point, NY 10996, \\ USA
}

\begin{abstract}
We explored repurposing discarded materials to construct simple, field expedient, solar heating devices capable of heating drinking water to water pasteurization temperatures. Results of different test configurations quickly constructed from junk material indicate important design parameters to include maximizing exposed container surface area and using transparent glass and dark absorbent material inside the solar heater box. The optimal configuration heated water to $69^{\circ} \mathrm{C}$ in a few hours demonstrating that a field expedient, zero cost solar heater capable of pasteurizing water $\left(65^{\circ} \mathrm{C}\right)$ can be quickly assembled from discarded material. Translating these key design parameters, rather than the exact design itself, to people in developing countries via relief organizations could help improve drinking water quality, reduce respiratory distress from indoor biomass burning, and potentially reduce the time and household income devoted to acquiring traditional biomass fuels. Organizations that operate in austere or disaster prone regions where safe drinking water may be unavailable may also benefit from knowing these design principles.
\end{abstract}

Keywords: Drinking water, water pasteurization, solar heating, adaptive reuse, disaster relief, field expedient.

\section{INTRODUCTION}

More solar energy strikes the Earth in one hour than the amount of energy used by humans in an entire year [1] making solar energy potentially the most abundant, versatile renewable energy source on Earth. Solar energy can be used to heat water, generate electricity, passively heat a home, cook food, and pasteurize water. The idea of using a solar cooker to cook food or pasteurize water is not new as solar cookers are ideal in principle from both economic and environmental perspectives. Roughly two to three billion people rely on solid biofuels (wood, crop residues, charcoal or animal dung) for energy, including the energy to cook food [2]. Collecting firewood, primarily a task assigned to women and children, is a time-consuming chore, especially as wood reserves become increasingly scarce and farther from home. Time spent collecting wood is time that could be used more productively for other pursuits such as education, growing food, or microeconomic projects. The requirement to invest significant time and money in collecting fuel can inhibit families from being productive, especially those who are impoverished. According to von Schirnding et al., some impoverished families spend more than $20 \%$ of disposable household income buying biofuels or devote more than $25 \%$ of total household labor to wood collection [3]. Once the wood is collected, it often fuels small indoor cooking fires. People in the vicinity of these smoky indoor fires, again generally women and small children, breathe sooty air and suffer consequent respiratory problems. The World Health Organization estimates that exposure to biomass smoke

*Address correspondence to this author at the Department of Geography and Environmental Engineering, United States Military Academy, West Point, NY 10996, USA; Tel: 845-938-4855; Fax: 845-938-3339;

E-mail: marie.johnson@usma.edu increases the risk of acute lower respiratory infections, such as pneumonia, chronic bronchitis, and chronic obstructive pulmonary disease, resulting in millions of deaths per year [3]. On a larger scale, the sooty air is also released to Earth's atmosphere contributing black carbon, which increases global warming via the greenhouse gas effect, and furthers climate change [4]. Finally, reliance on firewood as a source of fuel for water pasteurization and cooking leads to deforestation and ecosystem mismanagement as available woody biomass is collected for burning.

Devices that harness solar energy are promising because they have the potential to mitigate problems caused by using biomass to boil water or cook food. Solar energy is free, widely available, does not require time to gather, and produces no combustion products which contribute to indoor air pollution or climate change. Aid organizations have long recognized the potential for solar heating devices to improve the lives of the impoverished. Studies, however, have shown that the impact of solar cookers is often less than optimal [5-7]. The reasons solar cookers have not been widely adopted by those who could most benefit from them include initial expense, unfamiliarity, and lack of ability to maintain the cooker once acquired. Some of these barriers to adoption are caused by either selling solar cookers in stores, which requires an upfront financial commitment from the user, or by distributing free or subsidized solar cookers via aid organizations to families in need who may not be committed to their long-term use.

While researchers have examined ways to make solar heaters more efficient using complex designs or materials, few researchers have looked at rudimentary designs, and none have examined the use of discarded materials to create solar water pasteurizers. The feasibility of rudimentary solar water pasteurizers was explored by Danielsson and Elamzon [8], who reported that low cost solar cookers using designs 
made of simple, inexpensive parts (i.e., corrugated cardboard and aluminum foil) can be an effective alternative for cooking food and pasteurizing water. Similarly, Oelher and Scheffler [9] documented that meals can be cooked using solar energy and solar cookers built from locally available materials. Examples of other simple solar water pasteurizer designs include those constructed from cardboard and plastic bottles [10], clear plastic bags [11], clear plastic bottles [12], or cardboard coated with aluminum foil and clear plastic bottles [13]. Expanding on these ideas, our thought is to empower users to design and build their own effective solar heating devices from locally available discarded junk. Potentially, such heaters could be more readily accepted and have the feasibility to be disseminated rapidly through the local population. This approach capitalizes on the difference between giving a person a fish (a solar heater) and teaching a person to fish (teaching solar heating design principles). We hope that potential users will be empowered to build their own effective, cheap solar heating devices if taught the most critical design features and shown examples of successful solar heating devices capable of water pasteurization built from commonly discarded, locally available junk. People may be more likely to use a device long-term if they have built it with their own hands rather than having acquired it through an aid organization. Additionally, building an effective solar water pasteurizer from discarded junk will greatly reduce or eliminate upfront financial costs, thus eliminating another barrier to solar cooker adoption.

The target population for the successful incorporation of this idea is the urban poor. Impoverished people in urban areas may have very limited access to solid biomass fuels and may be unable to afford liquid fuels such as natural gas or propane for cooking. They are likely, however, to have access to discarded junk, some of which could potentially be used to build a solar heating device. In this paper, we focus on identifying the key solar heater design considerations and document a proof of concept idea that a working solar heater can be assembled from junk using minimal tools. Although urban areas are home to an astonishing variety of discarded materials, we specifically focus on building a drinking water pasteurizer using parts from junk cars.

\section{METHODS}

Our research is motivated by a desire to provide increased options for access to safe drinking water for those living or working in urban, resource poor areas in developing countries. While the type of material discarded varies from region to region, discarded items are commonplace in many urban areas. Our methods focused on a type of discarded material found in many locations: discarded vehicle parts. Our goal was to identify the most significant design characteristics to build an effective solar heater from this discarded material.

To test this concept, we created several easy to construct solar heater designs and developed a simple experimental methodology. First, we collected discarded junk car parts from a local automobile junk yard. The junk yard allowed us to scavenge in their yard and donated the selected parts at no cost. While identifying appropriate parts to test, we focused on three different functions: parts that could function as the base, parts that could trap or magnify sunlight, and parts that could serve as insulation to retain heat. To this end, we chose three different glass door windows, a black cloth covered foam seat cushion, an empty headlamp plastic bucket, a brake drum, a tire complete with wheel rim, and assorted cloth and insulation material from car interiors. While many other parts were available, we chose those parts that afforded us the opportunity to develop and test several different solar heater configurations. Table 1 provides a description of each configuration and the components used in each model.

After rinsing the collected parts with water and allowing them to air dry, we quickly built five different model solar heaters using the retrieved parts (Table 1). The model heaters were tested on the flat roof of our building, a location which minimized interference from curious on-lookers. Each model heater was tested by using it to heat a bottle of water in sunlight and recording water temperature with time. Identical 16.9 ounce water bottles were used in each experiment and the bottles were all filled to the same level so that the mass of water heated in each test was constant. Our test water was collected from Lusk Reservoir, an on-campus reservoir that serves as the intake to West Point's drinking water plant.

Each heater was built, loaded with a nearly full bottle of water, covered with one of the scavenged windows, photographed, and left to sit in the sun. About every 30 minutes, the glass was lifted, the bottle removed, the lid unscrewed, and a mercury thermometer inserted to measure water temperature. After recording the temperature, the bottle was recapped and returned to the heater. The entire procedure took about 30 seconds for each measurement; we presumed that water's high heat capacity would retard any decrease in temperature caused by periodic removal of the bottle from the heater. In addition, as a control, an identical bottle of water was placed adjacent to the heaters in direct sunshine but not in a solar heater. The water temperature of this control bottle was recorded in the same manner and at the same time as the water temperatures of the bottles in the test heaters. Heating water to $65{ }^{\circ} \mathrm{C}$ will kill all germs, viruses, and parasites, effectively pasteurizing water and making it safe to drink, so $65^{\circ} \mathrm{C}$ was our target temperature [10]. The tests ran from 10:30 am to 5:00 pm on two consecutive days in early August in New York approximately 55 miles north of New York City. Ambient temperatures were in the low 80's $\left(27-29{ }^{\circ} \mathrm{C}\right)$, average humidity was between $64 \%$ and $74 \%$, wind speed was between 5 and $8 \mathrm{mph}$, and cloud cover varied from sunny to partly cloudy. Incoming solar radiation normally peaks in New York between June and August and available solar radiation was less than $4.0 \mathrm{kWh} / \mathrm{m}^{2} /$ day for concentrating solar resources during the experiment [14]. Despite the summer months, available solar radiation in New York is relatively low when compared to locations at lower latitudes in the United States [14].

\section{RESULTS}

Five different solar water pasteurizing models were tested (Table 1) on two consecutive days. The change in water temperature with time for all five models is given in Fig. (2). On the first day, the control water bottle reached a high of $46{ }^{\circ} \mathrm{C}$ after four hours in the sun; on the second day, the control water bottle reached a high of $42{ }^{\circ} \mathrm{C}$ after three hours. One test design (Model 1) was a clear failure as it did 
Table 1. Models of Solar Water Pasteurizers Built from Junk Car Parts and Used to Heat Water

\begin{tabular}{|c|c|c|c|}
\hline Model & Base & Insulation & Cover \\
\hline \hline 1 & Headlamp $^{1}$ & Foam $^{2}$ & Clear window glass $^{3}$ \\
\hline 2 & Drum $^{4}$ & Insulation $^{5}$ and black cloth $^{6}$ & Mirrored window glass $^{7}$ \\
\hline 3 & Drum & Insulation and black cloth $^{\text {Clear window glass }}$ \\
\hline 4 & Tire $^{8}$ & Insulation, foam, and black cloth $^{\text {Clear window glass }}$ \\
\hline 5 & Tire & Insulation, foam, black cloth, and gasket $^{9}$ & Clear window glass $^{\text {None }}$ \\
\hline Control & None & None & None \\
\hline
\end{tabular}

${ }^{1}$ Headlamp is from standard truck or SUV.

${ }^{2}$ Foam is from inside of standard seat cushion.

${ }^{3}$ Clear window glass is translucent with no tinting and taken from a passenger door window.

${ }^{4}$ Tire brake drum found in standard car or truck.

${ }^{5}$ Insulation is cushioning material taken from inside of a passenger seat.

${ }^{6}$ Black cloth is material covering a passenger seat.

${ }^{7}$ Mirrored window glass is tinted glass from a passenger door window.

${ }^{8}$ Standard passenger vehicle tire.

${ }^{9}$ A gasket made of passenger seat foam was used to seal the space between the window and tire.

not reach water temperatures as hot as the control bottle (Figs. 1a, 2). Model 5 heated water the hottest and is also perhaps the easiest model to assemble. It consisted of a tire whose wheel rim was lined with insulating material and then covered by black cloth and then a transparent door window. Because of the slightly convex shape of the door window, the seal of the window against the tire was not air tight. We created a crude gasket of seat cushion foam to inhibit air exchange between the heater and the ambient environment (Fig. 1e). The water bottle in this most optimal solar heater reached pasteurization temperature within 3.5 hours and a maximum temperature of $69{ }^{\circ} \mathrm{C}$ in approximately 4 hours (Fig. 2).

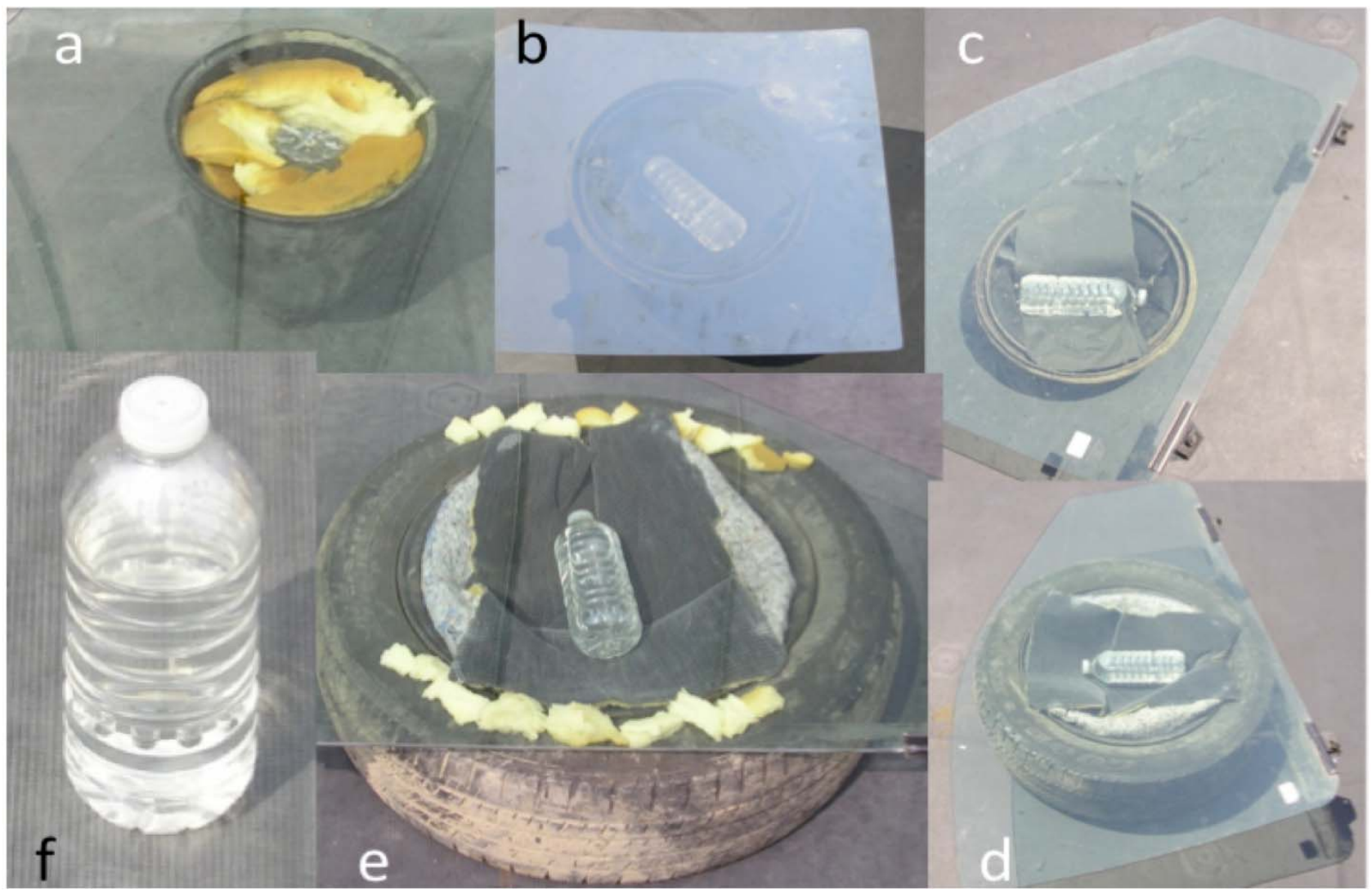

Fig. (1). Model solar heaters (Table 1) built from discarded car parts. (a) Model 1. (b) Model 2. (c) Model 3. (d) Model 4. (e) Model 5. (f) Control bottle of water. Note. Model 1: headlamp bucket filled with foam and covered by transparent glass. Model 2: brake drum lined with insulation and black cloth covered with mirrored glass. Model 3: brake lined with insulation and black cloth covered with transparent glass. Model 4: tire filled with insulation and black cloth covered with transparent glass. Model 5: tire filled with insulation and black cloth covered with transparent glass with gasket made of seat foam. 


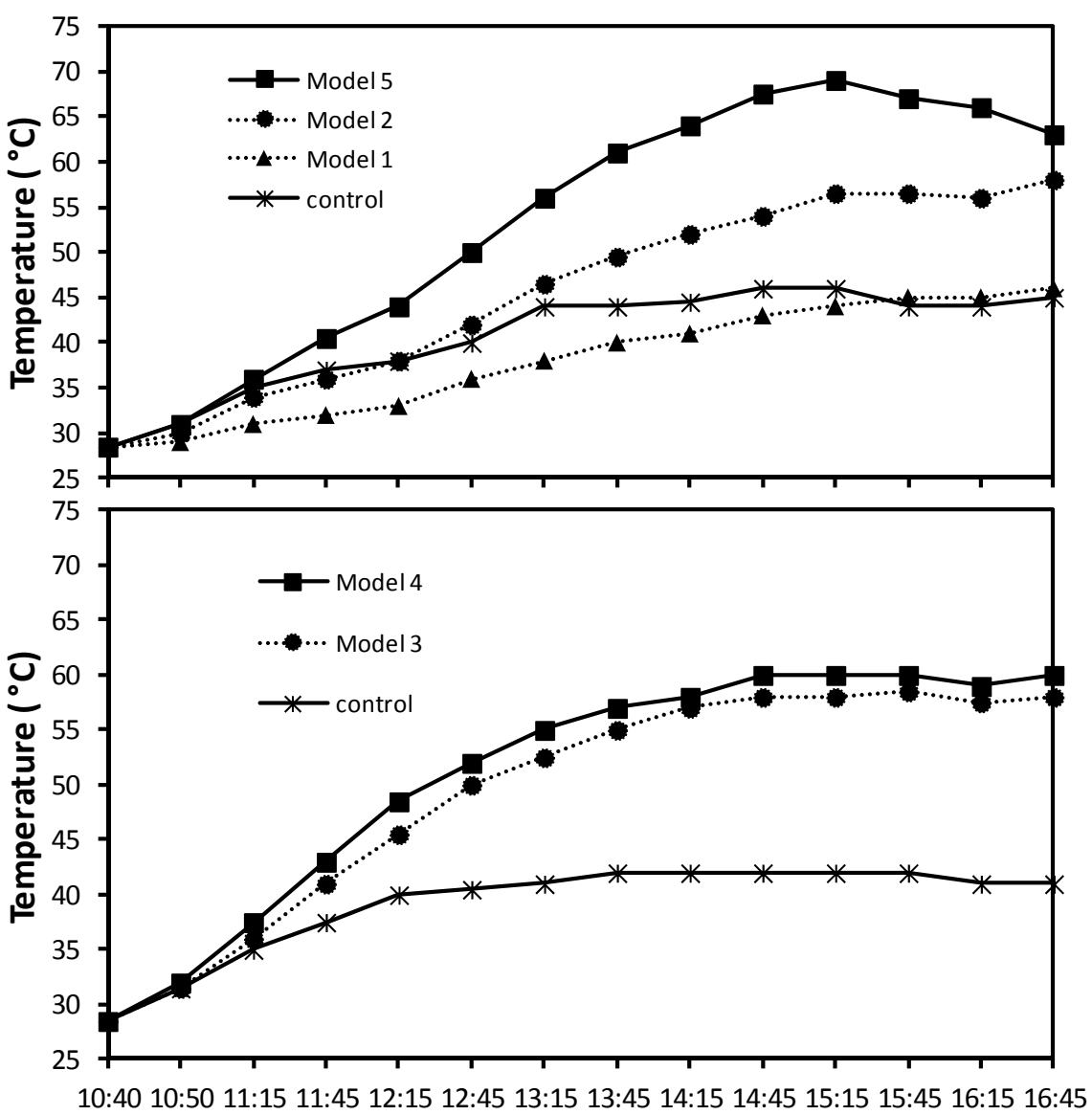

Time

Fig. (2). Water temperature as a function of time in bottles filled with water and placed in each model solar heater. The control shows the water temperature in a bottle placed in direct sunlight adjacent to but not in a solar heater.

The difference in water temperature between the control water bottle and each water bottle in each solar heater as a function of time is shown in Fig. (3). The failed design (Fig. 1a, Model 1) is clearly evident as the data set showing a temperature cooler than the control bottle. The heater that was made from a brake drum covered with a semi-opaque door window (Model 2) showed the second lowest rise in temperature. The other three designs showed similar temperature increases, with the optimal configuration (tire with gasket, Model 5) showing an eventual $5{ }^{\circ} \mathrm{C}$ advantage over the next best design (Model 4, Fig. 3).

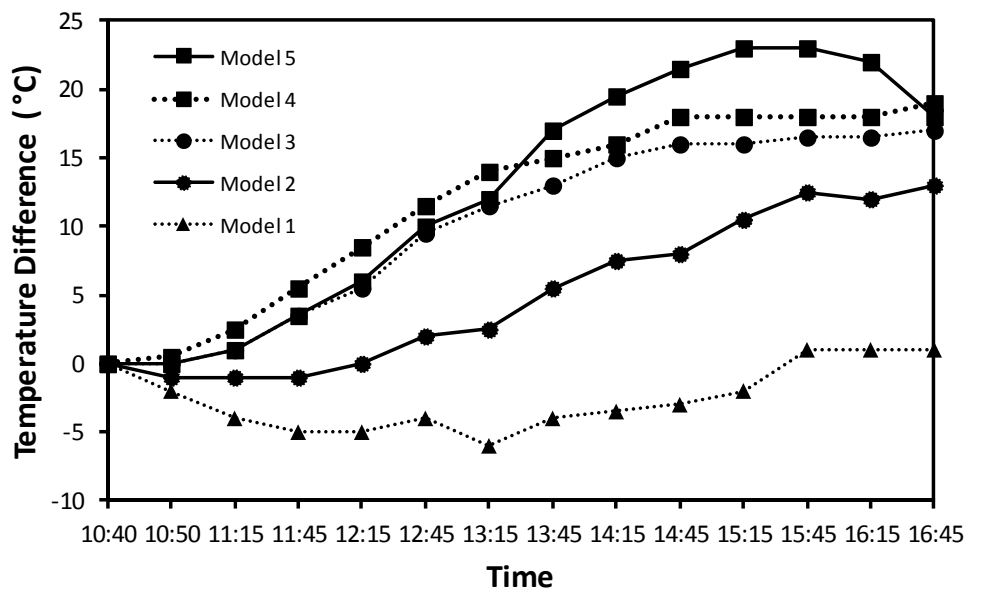

Fig. (3). The temperature difference as a function of time between water in a bottle heated in each model solar heater and water in a control bottle in direct sunlight adjacent to but not in a solar heater. 


\section{DISCUSSION}

The wide differences in maximum water temperatures between the test models and control bottles (from $5{ }^{\circ} \mathrm{C}$ cooler to $23{ }^{\circ} \mathrm{C}$ hotter) reveal which design parameters most effectively promote heating. The design which resulted in the lowest maximum temperature (Model 1) was unique in that it had the least amount of bottle surface area exposed to the sun; it was the only design where the bottle was on its end in the solar heater rather than its side (Fig. 1a). In this design, the end of the bottle was exposed to sunlight while the majority of the bottle was wrapped in insulating material. Rather than serving to trap heat in the bottle, the insulation prevented the water from being heated. Model 2 resulted in the second lowest maximum temperature. This design utilized a tinted rather than transparent window as the heater cover. These results indicate that the two design parameters which affected maximum temperature gain most strongly are (1) exposing the maximum surface area of the bottle to the sun and (2) using transparent glass. These design keys resulted in an increased gain of between 10 and $20^{\circ} \mathrm{C}$ when compared to the control bottle for similar times in the sun (Models 3 and 4). Finally, the addition of a crude, homemade gasket to seal the slightly convex shaped window against the tire resulted in an additional increase of $5{ }^{\circ} \mathrm{C}$ relative to not using a gasket (Model 4 vs Model 5, Fig. 2).

These test results demonstrate that with very minor modifications, a field expedient, zero cost solar heating device capable of heating water to $65{ }^{\circ} \mathrm{C}$, and thus pasteurizing it, can be assembled from junk car parts. If the design keys (i.e., maximum bottle surface area exposed to the sun, transparent glass, reduced air transfer, box lined with dark absorbent material) are well publicized, then the hope is that people forced to rely on unsafe drinking water sources could make effective, cheap solar heaters in the field with little training. Once assembled, such a solar heater will kill viruses, bacteria and parasites in non-potable water while requiring no future maintenance, operation or fuel costs. An additional benefit to these solar pasteurizer designs is that the pasteurization process creates a positive synergy between both the heat and the ultraviolet light of the sun. Joyce $\mathrm{et} \mathrm{al}$. [15] using a similar testing scenario in Kenya indicated that even turbid water samples heavily contaminated with Escherichia coli can be completely disinfected with no bacterial recovery due to the synergistic effects of heat and UV light.

Our test designs heated only small quantities of water (17 ounces). To be practical in the real world, our design principles need to be scaled up to pasteurize larger amounts of water in a reasonable amount of time (for example, 5 gallons per day). In theory, the design principles we have identified here are flexible and scaling is simply a matter of finding key components in larger sizes. Specifically, material to serve as the heater base, the heater cover and as insulation needs to be identified. In addition, either many small bottles or fewer large bottles would need to be scavenged to serve as the water containers inserted in the improvised solar heaters. In either case, the key would be finding transparent covers (window glass) and material (such as torn seat cushion foam) to seal the edges of the cover against the heater box to reduce air transfer. These key design principles are demonstrated convincingly by the water temperatures achieved in Model 5 .
While the environmental, economic, and time-saving advantages of using a solar heater are undeniable, use of solar cookers may not be successful in all situations. For the concept of a solar heater made from junk parts to be adapted and implemented successfully, several key factors must be present. First, incoming solar radiation must be sufficient; second, discarded waste must be available; third, solar cookers must be viewed positively by the local culture, which must recognize and embrace their distinct advantages. We believe that a solar heater created from discarded material will likely meet these criteria in many scenarios, especially in regions of high insolation where junk parts are abundant.

Regions with strong insolation (i.e. greater than 4.0 $\mathrm{kWh} / \mathrm{m}^{2} /$ day) are likely best for simple solar heater designs [10]. In general, equatorial regions are most likely to fulfill this environmental requirement. Solar heaters designed from junk parts could be utilized effectively, however, in other regions as well. These regions include those subject to infrequent natural, or potentially manmade, disasters such as hurricanes, earthquakes, volcanic eruptions, or riots and civil unrest. In the event of such a disaster, impromptu solar heater construction from junk parts may be very beneficial as existing infrastructure to clean and treat drinking water may be decimated by the event. Examples of recent disasters where junk parts were widely available and solar heater construction may have provided pasteurized water include Hurricane Katrina in Louisiana in 2005, the magnitude 7 2010 earthquake in Haiti, flooding in the Indus River Basin of Pakistan in 2010, and the earthquake and resulting tsunami which affected the Pacific coast of Japan in 2011. While developed countries may be able to deploy more technologically advanced drinking water and cooking solutions in a relatively short time, even within hours of the disaster, some developing countries may not have access to safe drinking water or cooking fuels for days or weeks. Solar heaters constructed from commonly discarded materials can fill this immediate need until long-term relief is available.

In addition to favorable environmental circumstances, discarded junk, such as car parts, must be readily available. Urban or peri-urban environments are most likely to have the quantity and type of discarded material required for the building of an improvised solar heater. For the proof-ofconcept study presented here, we tested solar heaters designed and made from car parts as cars are increasingly common in developing countries. For example, the total production of motor vehicles increased sevenfold between 1950 and 2008, with many being used in urban areas of developing countries [16]. Other sources of junk parts that may be widely available and appropriate for solar heater design include discarded household appliances, cardboard waste, various plastic packaging waste, glass containers, and construction materials such as discarded storm windows.

An important consideration for organizations attempting to implement solar heater or cooker adaption programs is acceptance by the local user. Currently, solid biomass, usually firewood and dried animal dung, is the most prevalent cooking fuel in developing nations [2]. Some estimates indicate that approximately $90 \%$ of people living in developing countries do not have access to sustainable fuel sources [17]. Creating a positive impression of solar 
heaters to those living in developing countries has proven to be challenging in many regions, and several research studies have produced mixed results. Ahmad [5] found that some families in Gujarat, India chose not to use solar cookers because they did not have suitable space in their living area, other families could not adjust to the routine of using a solar cooker, and others still were simply not interested in using solar power. Additional studies have shown conflicting results concerning the implementation of solar cookers in different regions of Africa, primarily relating to acceptance of the technology and perceived ease of use [18-20].

Masera et al. [21] proposed that acceptance of cooking techniques that do not rely on the use of biomass for fuel, such as solar cooking, relies on economics and access to fuels, technical characteristics, cultural preferences, and health impacts. Solar heaters constructed from discarded materials successfully address these four key factors. First, designing and building a solar heater eliminates the stigma of receiving a handout from an aid organization and avoids any hefty initial financial investment. This method also eliminates on-going operation and maintenance costs as the fuel (sunshine) is free. Second, solar heaters are simple to operate and not technically complex. Building them from junk parts can be accomplished without using a tool more complex than a knife, as demonstrated in this project. Third, since a solar heater made with discarded junk is designed and built by the individual user, pride in using the cooker may increase. An additional consideration is that since the heater is made from widely-available, free junk parts, fears about theft of the heater while left unattended in the sun for long hours may be diminished. Lastly, minimal health concerns exist with constructing a heater from junk parts as the junk parts are never in direct contact with food or water. Additionally, pasteurizing water with sunshine rather than boiling water over smoky biomass fires will improve indoor air quality and lessen the respiratory illnesses associated with regularly breathing dirty, sooty air.

We propose a model in which local leaders are educated about solar heater design principles rather than given solar heaters. This education and perhaps a demonstration of effective solar heaters built from available local junk could be championed by non-governmental or relief organizations located in regions of concern. Leaders in these organizations can determine whether solar heaters, especially those made from junk, are a viable option to pasteurize water and cook food. Several relief organizations can potentially benefit from learning the key principles of designing field expedient solar heaters from junk parts and may employ these techniques in training locals or in natural or man-made disaster emergency situations. Organizations that could adopt this approach include Engineers Without Borders, who have already employed solar cookers in projects [22], and while additional optimization would be required, medical organizations such as the Red Cross, who could employ solar heating devices to sterilize equipment [23]. The Renewable Energy Disaster Relief Fund published a report on the usage of solar cookers during disaster relief operations in the United States [24], so such cookers have a potential role in every country. Use of solar heaters and cookers by military units operating in austere conditions during deployments or in relief operations could also prove advantageous to pasteurize water for soldiers as well as affected locals.

\section{CONCLUSION}

This study examined rapidly designing and building cheap, effective solar heaters from junk car parts using minimal tools. In all, five different model solar heaters were built and used to heat water. The most efficient designs were determined by comparing the maximum water temperature reached in a bottle heated by each model heater and also by comparing the water bottle temperatures heated in the solar heaters to a control water bottle simply placed in direct sunlight. The test results highlight the key design features. We hope that by identifying these key design elements rather than specifying a particular design and by demonstrating that solar water pasteurizers can be built by hand from junk, aid organizations can achieve rapid implementation of solar heaters in emergency situations or perhaps for long-term everyday household use. Once educated about key design criteria and the features to search for in discarded junk, anyone could collect suitable junk and design their own simple and effective solar heater to pasteurize drinking water.

\section{CONFLICT OF INTEREST}

The authors confirm that this article content has no conflict of interest.

\section{ACKNOWLEDGEMENTS}

Declared none.

\section{REFERENCES}

[1] Lewis NS. Toward cost effective solar energy use. Science 2007; 315: 798-801.

[2] Bailis R, Ezzati M, Kammen DM. Greenhouse gas implications of household energy technology in Kenya. Environ Sci Technol 2003; 37: 2051-9.

[3] von Schirnding Y, Bruce N, Smith K, Ballard-Tremeer G, Ezzati M, Lvovsky K. Addressing the impact of household energy and indoor air pollution on the health of the poor: Implications for policy action and intervention measures. Paper prepared for the Commission on Macroeconomics and Health, World Health Organization, Washington DC. Based in parts on the proceedings of a WHO-USAID Global Consultation on the Health Impact of Indoor Air Pollution and Household Energy in Developing Countries, Washington DC: May 2000.

[4] Ramanathan V, Carmichael G. Global and regional climate changes due to black carbon. Nat Geosci 2008; 1: 221-7.

[5] Ahmad B. Users and disusers of box solar cookers in urban India Implications for solar cooking projects. Sol Energy 2000; 69: 1-6: 209-15.

[6] Wentzel M, Pouris A. The development impact of solar cookers: A review of solar cooking impact research in South Africa. Energy Policy 2007; 35: 1909-19.

[7] Yadav B, Yadav S, Yadav L. Perception and attitude of rural women towards solar cookers. Indian Res J Exten Educ 2009; 9(1): $22-4$

[8] Danielsson J, Elamzon J. Development of a technical, economical and environmental sustainable solar oven technology - A Field Study in Sri Lanka. Thesis. Program of renewable energy engineering, Sweden: Halmstad University 2005

[9] Oelher U, Scheffler W. The use of indigenous materials for solar conversion. Sol Energy Mat Sol C 1999; 33: 379-87.

[10] Ciochetti DA, Metcalf RH. Pasteurization of naturally contaminated water with solar energy. Appl Environ Microbiol 1984; 47: 223-8.

[11] Lawand TA, Ayoub J, Gichenje H. Solar disinfection of water using transparent plastic bags. REIC Int Energy J 1997; 19(1): 3744.

[12] McGuigan KG, Joyce TM, Conroy RM, Gillespie JB, ElmoreMeegan M. Solar disinfection of drinking water contained in 
transparent plastic bottles: characterizing the bacterial inactivation process. J Appl Microbiol 1998; 84: 1138-48.

[13] Safapour N, Metcalf R. Enhancement of solar water pasteurization with reflectors. Appl Environ Microbiol 1999; 65(2): 859-61.

[14] National Renewable Energy Laboratory Concentrating Solar Power Map: Available from: http://www.nrel.gov/gis/solar.html. Accessed September 3, 2013.

[15] Joyce TM, McGuigan KG, Elmore-Meegan M. Conroy RM. Inactivation of fecal bacteria in drinking water by solar heating. Appl Environ Microbiol 1996; 62(2): 399-402.

[16] Cooper D, Alley FC. Air pollution control: A design approach. Long Grove, Illinois: Waveland Press 2011; pp. 575-7.

[17] Barnes DF, Floor WM. Rural energy in developing countries: A challenge for economic development. Ann Rev Energ Environ 1996; 21: 497-530.

[18] Eberhard AA. Dissemination of solar ovens in Lesotho: Problems and lessons. Proceedings of the Eighth Biennial Congress of the
International Solar Energy Society; New York: Pergamon Press 1984.

[19] Biermann E, Grupp M, Palmer R. Solar cooker acceptance in South Africa: Results of a comparative field test. Sol Energ 1999; 66(6): 401-7.

[20] Kimambo CZM. Development and performance testing of solar cookers. J Energ South Afr 2007; 18(3): 41-51.

[21] Masera OR, Saatkamp BD, Kammen DM. From linear fuel switching to multiple cooking strategies: A critique and alternative to the energy ladder model. World Dev 2000; 28(12): 2083-103.

[22] Helgesson C. Engineers Without Borders and their role in humanitarian relief. IEEE Eng Med Biol Mag 2006; 25(3): 32-5.

[23] Kerr BP, Scott J. Use of the solar panel cooker for medical pressure steam sterilization. Kerr-Cole Sustainable Living Center. Taylor, AZ 2006; p. 6

[24] Young W, Reinarts R. Solar 2007: Renewable energy disaster relief fund gives a helping hand. Florida Solar Energy Center, Cocoa, FL. FSEC-PF-431-08; 2007

(C) Johnson and Pfluger; Licensee Bentham Open.

This is an open access article licensed under the terms of the Creative Commons Attribution Non-Commercial License (http: //creativecommons.org/licenses/by$\mathrm{nc} / 3.0 /$ ) which permits unrestricted, non-commercial use, distribution and reproduction in any medium, provided the work is properly cited. 